\title{
Efektivitas Implementasi Program Keluarga Harapan (PKH) Dalam Upaya Penanggulangan Kemiskinan (Studi Pada Dinas Sosial Kabupaten Blitar)
}

\author{
The Effectiveness of the Implementation of the Program Keluarga Harapan \\ (PKH) in Poverty Alleviation Efforts (Study at the Blitar District Social Service)
}

\author{
Anwar Hakim Darajat ${ }^{1}$, Septa Ekasari ${ }^{2}$ \\ ${ }^{1}$ Fakultas Ilmu Sosial dan Ilmu Politik, Universitas Islam Balitar \\ Jl. Majapahit No. 2 - 4, Blitar, Indonesia \\ ${ }^{2}$ Fakultas Ilmu Sosial dan Ilmu Politik, Universitas Islam Balitar \\ Jl. Majapahit No. 2 - 4, Blitar, Indonesia \\ Email: anwarhakim_nina@yahoo.com
}

\begin{abstract}
ABSTRAK
Secara umum efektivitas menyatakan sampai seberapa besar tercapaianya suatu tujuan yang proses awalnya ditentukan dengan target. Pengukuran tingkat efektivitas dilakukan dengan membandingkan rencana yang ditentukan dengan hasil nyata yang direalisasikan. Beberapa upaya telah dilakukan oleh Pemerintah Indonesia untuk menanggulangi berbagai problematika kemiskinan, salah satunya melalui Program Keluarga Harapan (PKH). Keluarga Penerima Manfaat (KPM) sebagai salah satu penerima program bantuan sosial bersyarat yang ditetapkan sebagai penerima manfaat Program keluarga Harapan (PKH). Tujuan penelitian ini adalah mengetahui efektivitas implementasi Program Keluarga Harapan (PKH) dalam upaya penanggulangan kemiskinan serta mengetahui kendala-kendala Program Keluarga Harapan (PKH) dalam upaya peanggulangan kemiskinan. Metode penelitian menggunakan pendekatan deskriptif kualitatif. Hasil penelitian menunjukkan efektivitas implementasi Program Keluarga Harapan (PKH) sudah dapat dikatakan efektif dalam upaya penanggulangan kemiskinan dilihat dari beberapa indikator efektivitas, tetapi masih terdapat beberapa kendala diantaranya kehilangan ATM, pemahaman sosialisasi yang masih kurang diterima, terjadinya selisih paham antar stakeholder serta medan yang sulit. Saran memberikan sosialisasi ulang tentang Program Keluarga Harapan (PKH) kepada stakeholder agar Program Keluarga Harapan $(\mathrm{PKH})$ bisa tepat sasaran ke masyarakat serta perbaikan medan yang sulit agar daerah yang sulit dapat terjangkau.
\end{abstract}

Kata kunci: Efektivitas, Tingkat efektivitas, Program Keluarga Harapan (PKH)

\section{ABSTRACT}

Effectiveness in general states the extent to which a goal has been achieved whose initial process is determined by the target. Measuring the level of effectiveness is done by comparing the determined plan with the tangible results that are realized. Various efforts have been made by the Government of Indonesia to overcome various problems of poverty, one of which is through the Program Keluarga Harapan (PKH). Keluarga Penerima Manfaat (KPM) as one of the 
recipients of the conditional social assistance program who are designated as beneficiaries of the Program Keluarga Harapan (PKH). The purpose of this study was to determine the effectiveness of the implementation of the Program Keluarga Harapan (PKH) in poverty reduction efforts and to find out the constraints of the Program Keluarga Harapan (PKH) in poverty reduction efforts. The research method used a qualitative descriptive. The results show that the effectiveness of the implementation of the Program Keluarga Harapan (PKH) can be said to be effective in poverty reduction efforts seen from several indicators of effectiveness, but there are still some obstacles including losing ATMs, understanding of socialization that is still not accepted, the difference in understanding between stakeholders and the difficult terrain. Suggestions provide re-socialization of the Program Keluarga Harapan (PKH) to stakeholders so that the Program Keluarga Harapan $(P K H)$ can be right on target to the community and repair difficult terrain so that difficult areas can be reached.

Keywords: Effectiveness, level of effectiveness, Program Keluarga Harapan (PKH)

\section{PENDAHULUAN}

Kemiskinan merupakan keadaan yang tidak mudah didefinisikan dan bersifat multidimensi karena kemiskinan masih menjadi beban permasalahan maysrakat dan pemerintah yang belum dapat diselesaikan. Banyak faktor yang membuat penanggulangan menjadi tidak mudah ditangani diantaranya keadaan sosial, agama, budaya, pola pikir masyarakat, gaya hidup, semangat juang, psikologi masyarakat, dan berbagai hal lain. Dalam penanggulangan kemiskinan sendiri dibutuhkan pula konsistensi dari sebuah kebijakan.

Pemerintah Indonesia telah melaksanakan beberapa upaya untuk menanggulangi problematika kemiskinan, salah satunya melalui kebijakan berasaskan pelindungan dan bantuan sosial yang berupa pemenuhan kebutuhan dasar individu maupun rumah tangga tergolong miskin seperti pelayanan kesehatan, pendidikan, pangan, air bersih dan sanitasi. Pemerintah Indonesia juga telah mengadakan beberapa program bantuan untuk individu, keluarga atau kelompok masyarakat yang dianggap kurang mampu, seperti Program Keluarga Harapan (PKH), Penanggulangan Feminisasi Kemiskinan, Bantuan Pangan Non Tunai, Bantuan Rumah Tangga Sangat Miskin, Kartu Indonesia Sehat (KIS), Program Bantuan dan Perlindungan Sosial, Bantuan Operasional Sekolah (BOS), Kartu Indonesai Pintar (KIP), Bantuan stimulan perumahan swadaya, dan berbagai program lainnya. 
Sebagai salah satu bentuk kebijakan yang menitik beratkan pada bidang kesehatan dan pendidikan untuk anak-anak dari KPM, Program Keluarga Harapan (PKH) merupakan program yang memberikan bantuan sosial dengan harapan kelak akan memutus mata rantai kemiskinan melalui investasi pada kedua bidang tersebut. Sebagai upaya menanggulangi tingkat kemiskinan, sejak tahun 2007 PKH telah dilaksanakan oleh Pemerintah Indonesia. Dalam penanggulangan kemiskinan yang dihadapi oleh beberapa negara, program perlindungan sosial cukup terkenal di kancah internasional dengan istilah Conditional Cash Transfers (CCT) terbukti dalam pelaksaannya cukup berhasil, terutama mengatasi masalah kemiskinan yang kronis.

Menurut Siagian (2001 : 24) mengemukakan bahwa efektivitas pada dasarnya menampakkan pada tingkat keterjangkauan suatu hasil. Efektivitas seringkali terpaut dengan pemahaman efisien, tetapi sebenarnya berbeda. Efektivitas memusatkan pada hasil yang diperoleh, sedangkan efisiensi lebih menekankan pada proses untuk memperoleh suatu hasil yang diinginkan melalui perbandingan dari segi output dan inputnya. Menurut Ripley Franklin (dalam Winarno, 2012:147) implementasi merupakan sesuatu yang tercipta setelah suatu undang-undang ditetapkan untuk memberikan kebijakan, otoritas dari program, keuntungan atau suatu model dari hasil yang terealisasi (tangible otput).

Sehubungan dengan pendapat Gordon (dalam Pasolong, 2013), menyatakan bahwa implementasi berkaitan dengan beberapa kegiatan yang ditujukan pada realisasi suatu program. Kewajiban seorang administrator ialah membangun dan mengendalikan suatu cara untuk mengkoordinasikan, menginterpretasi dan mengimplementasikan kebijakan yang lolos untuk diseleksi. Mengkoordinasi berarti mengelola berbagai unit, sumber daya, dan dalam menjalankan program yang menjadi tujuan. Menginterprestasi berkaitan dengan menafsirkan berbagai sebutan dari program agar layak dan mudah diterima ke dalam beberapa rencana. mengimplementasi berarti menggunakan pelayanan secara rutin dengan melaksanakan beberapa instrumen untuk, melaksanakan berbagai pembayaran.

Suatu kebijakan apabila tidak direncanakan dan dipersiapkan dengan baik dalam implementasinya, maka tujuan dari kebijakan tersebut tidak dapat diwujudkan. Berkaitan dengan penataan kepentingan publik Shafritz dan Russel 
(2005:55) berpendapat proses menempatkan program pemerintah yang menerjemahkan mandat hukum baik dilakukan dengan perintah eksekutif atau statu yang berlaku sesuai arahan dan struktur program tersebut untuk memberikan layanan yang terbaik dan efek yang kreatif merupakan pengertian suatu implementasi. Memahami bagaimana realita yang akan tercipta menjadi fokus perhatian dari implementasi kebijakan itu sendiri, setelah suatu program dinyatakan berlaku dan diharapkan untuk mencapai tujuan yang memberikan suatu dampak.

\section{METODE PENELITIAN}

Peneliti menggunakan metode kualitatif dikarenakan pengolahan data yang didapatkan dari hasil penelitian berupa lisan secara langsung atau kata-kata yang tertulis, sehingga peneliti dapat menyajikan hasil hubungan antara informan atau narasumber dengan peneliti secara lebih mendalam. Peneliti berupaya untuk memahami, menjelaskan dan mendeskripsikan secara menyeluruh sebagaimana program keluarga harapan $(\mathrm{PKH})$ berupaya menurunkan kemiskinan sehingga untuk mengungkapkan tujuan penelitian, yakni bagaimana efektivitas dari implementasi Program Keluarga Harapan (PKH) dalam upaya menurunkan kemiskinan, maka akan digunakan metode deskriptif melalui pendekatan kualitatif.

Peneliti menggunakan 3 (tiga) teknik untuk mengumpulkan data, yaitu : teknik wawancara, observasi dan teknik dokumentasi. Peneliti menggunakan teknik analisa yang diungkapkan oleh Miles dan Huberman, yaitu : teknik mereduksi data ( mengarahkan hasil wawancara untuk menarik kesimpulan ), penyajian data ( mengumpulkan hasil wawancara dengan bentuk teks naratif untuk mengambil kesimpulan) dan penarikan kesimpulan ( menarik hasil dari reduksi dan penyajian data untuk mengambil suatu tindakan). Analisis data merupakan metode mencarai dan menyusun data yang diperoleh secara sistematis dari hasil catatan di lapangan, wawancara, dan beberapa bahan lain, agar lebih mudah untuk difahami dan apa yang ditemukan dapat dibagikan kepada masyarakat (Bodgan dalam Sugiyono, 2013:244). 


\section{HASIL DAN PEMBAHASAN}

Sebagai bantuan sosial bersyarat, Program Keluarga Harapan (PKH) membuka akses bagi keluarga yang tergolong miskin terutama untuk ibu hamil dan anak-anak dengan memanfaatkan berbagai macam fasilitas layanan kesehatan (askes) dan fasilitas layanan untuk pendidikan (fasdik). Masalah Program Keluarga Harapan $(\mathrm{PKH})$ sendiri juga mulai dipercepat untuk melingkupi lanjut usia hingga penyandang disabilitas dengan tetap menjaga tingkat kesejahteraan sosialnya. Maka dari itu, penelitian ini bertujuan untuk mengetahui bagaimana efektivitas pada implementasi Program Keluarga Harapan (PKH) dalam melakukan upaya penanggulangan kemiskinan dapat dilihat melalui indikator efektivitas, yakni :

1. Ketepatan perhitungan biaya

Bantuan yang didapatkan di setiap keluarga berbeda-beda sesuai dengan jumlah tanggungan yang ada di setiap keluarga, karena komponen penerima Program Keluarga Harapan $(\mathrm{PKH})$ dari setiap keluarga sifatnya berbeda dan maksimal penerima Program Keluarga Harapan $(\mathrm{PKH})$ dalam satu kelurga adalah empat orang saja.

\section{Ketepatan tujuan}

Tujuan dari Program Kelurga Harapan $(\mathrm{PKH})$ adalah secara garis besar Program Keluarga Harapan (PKH) fokus pada segi pendidikan dan kesehatan para penerima manfaat Program Kelurag Harapan (PKH) serta memberdayakan masyarakat yang dianggap kurang mampu dalam hal ekonomi maupun segi lainnya.

3. Ketepatan berfikir

Program Keluarga Harapan (PKH) sangat berpengaruh terhadap kelangsungan hidup Keluarga Penerima Manfaat (KPM). Apabila Keluarga Penerima Manfaat (KPM) sudah mampu mencukupi kehidupannya sehari-hari maka yang bersangkutan secara sukarela akan mengundurkan diri dari kepesertaan Program Keluarga Harapan (PKH).

4. Ketepatan sasaran

Sasaran dari penerima manfaat Program Keluarga Harapan (PKH) merupakan keluarga yang rentan terdaftar dan tergolong miskin dalam Data Basis 
Terpadu Program Penanganan Fakir Miskin yang memiliki beberapa komponen, seperti anak berusia 0 sampai dengan 6 tahun dan ibu hamil atau menyusui merupakan kriteria dari komponen kesehatan, kriteria dari komponen pendidikan seperti anak sekolah SD/MI sampai anak sekolah SMA/MA dan komponen lanjut usia memiliki kriteria yang diutamakan yaitu penyandang disabilitas berat dan lanjut usia 60 tahun keatas.

Berdasarkan hasil wawancara terdapat beberapa kendala-kendala yang dihadapi Program Keluarga Harapan (PKH) dalam upaya penanggulangan kemiskinan, diantaranya jika ATMnya hilang, maka Dinas Sosial selaku fasilitator Program Keluarga Harapan (PKH) harus membuatkan surat rekomendasi kehilangan kepada pihak bank, pemahaman Keluarga penerima Manfaat (KPM) terhadap sosialisai yang sudah dilakukan pendamping maupun koordinator masih sulit dicerna, masih terjadi selisih paham antara stakeholder serta jangkauan desa yang jauh dan medan yang sulit membuat terkendalanya bantuanProgram Keluarga Harpan (PKH) masuk dan pertemuan antar Keluarga Penerima Manfaat (KPM) terhambat.

\section{KESIMPULAN DAN SARAN}

Efektivitas dan implementasi program keluarga harapan $(\mathrm{PKH})$ sudah dapat dikatakan efektif dalam upaya penanggulangan kemiskinan dilihat dari beberapa indikator efektivitas diantaranya ketepatan perhitungan biaya, sasaran, tujuan dan berfikir. Program Keluarga Harapan (PKH) dapat membantu meringankan beban hidup masyarakat dan memiliki pengaruh terhadap kehidupan Keluarga Penerima Manfaat (PKM) dalam bidang pendidikan dan kesehatan.

Jika terjadi kesalahan seperti menghilangkan ATM, maka Dinas Sosial selaku fasilitator Program Keluarga Harapan (PKH) harus membuatkan surat rekomendasi kehilangan kepada pihak bank, pemahaman Keluarga Penerima Manfaat (KPM) terhadap sosialisai yang sudah dilakukan pendamping maupun koordinator masih sulit dicerna, masih terjadi selisih paham antara stakeholder serta jangkauan desa yang jauh dan medan yang sulit membuat terkendalanya bantuan Program Keluarga Harapan (PKH). 


\section{DAFTAR PUSTAKA}

Pasolong, Harbani. 2013. Teori Administrasi Publik. Alfabeta. Bandung.

Shafritz, Jay M. and E W. Russel. 2005. Introducing Public Administration. Pearson Education Inc. New York.

Siagian, Sondang P. 2001. Manajemen Sumber Daya Manusia. Bumi Aksara. Jakarta

Sugiyono. 2013. Metode Penelitian Kuantitatif, Kualitatif dan R\&D. Alfabeta. Bandung.

Winarno, Budi. 2002. Kebijakan Publik (Teori, Proses dan Studi Kasus). Caps. Jakarta. 